\title{
"Asunción": el origen del lenguaje líquido en Samuel Beckett
}

Fecha de envío 15 de agosto de 2020

Fecha de aceptación: 5 de septiembre de 2020

\begin{abstract}
Resumen
El campo semántico del agua y de los fenómenos que pueden asociársele (la lluvia, la sed, el ahogo) es harto recurrente en la obra de Beckett. Partiendo de la idea de que este imaginario se encuentra ligado a reflexiones en torno al lenguaje, este trabajo se propone como una indagación sobre el complejo aparato metafórico que articula en términos metaliterarios y lingüísticos en sus formulaciones iniciales en "Asunción" (1929), su primer relato, y en Sueño con mujeres que ni fu ni fa, su primera novela, escrita en 1932. El análisis se complementará con una aproximación a la cuestión en la "Carta alemana" de 1937 que Beckett dirige a Axel Kaun. Se parte de la hipótesis de que este imaginario acuático presenta una estrecha vinculación con la concepción sobre el lenguaje en Beckett y, en particular, con su exploración de la expresión del silencio como límite de la literatura en su poética.
\end{abstract}

Palabras clave: agua, lenguaje, silencio, poética.

\section{“Asunción”: the origin of liquid language in Samuel Beckett}

\begin{abstract}
The semantic field of water and of related phenomena (rain, thirst, drowning) is recurrent in Beckett's works. On the basis of a liaison between this imagery and the author's ideas around language, this article explores the complex metaphorical apparatus that water articulates in metaliterary and linguistic terms in its initial formulations in "Assumption" (1929), Beckett's first published story, and in Dream of fair to middling women, his first novel, written in 1932. The analysis will be complemented with an approach to the matter in the german letter of 1937 to Axel Kaun. The investigation is
\end{abstract}


sparked by the idea that this liquid imagery is linked to Beckett's ideas around language, and, particularly around the exploration of silence as literature's limit in his poetics.

Keywords: water, words, silence, poetics.

La sentencia griega de que "no se puede entrar dos veces en el mismo río", se hace extensiva al lenguaje. Fritz Mauthner ${ }^{1}$

\section{Introducción}

El agua, o en un sentido más amplio, los cuerpos de agua -los ríos, los lagos, el mar- y los fenómenos asociados a ellos (como pueden ser la lluvia, la neblina, pero también la amenaza de la sed o incluso la del ahogo), constituyen un campo semántico harto recurrente en la obra de Samuel Beckett. La pieza radiofónica Embers transcurre a orillas del mar, cuyo sonido llena los silencios entre los parlamentos y perturba a Henry; Nagg y Nell recuerdan casi haberse ahogado en el Lago Como en Endgame; Gogo rememora su intento de suicidio en un río en Esperando a Godot; la logorrea de Mouth en Not I se expresa como un "arroyo constante" ("steady stream"); mientras que, en un poema como "Dieppe", el yo lírico se identifica con un río de arena ("je suis ce cours de sable qui glisse") (Beckett: 1970, p. 93); por último, en un hecho de particular relevancia a los fines de este estudio, el mismo Beckett recurre a este imaginario para reflexionar sobre su escritura en la famosa carta a Axel Kaun. Las imágenes líquidas atraviesan la obra del autor en su conjunto, desde su primera etapa de producción y reapareciendo y resignificándose tanto en obras de teatro como de radio, en narrativa, en poemas, e incluso por fuera de lo que podríamos definir estrictamente como parte del corpus literario beckettiano, en su correspondencia.

Desde sus inicios como escritor, Beckett comparte con James Joyce -con quien tuvo un vínculo muy cercano y fructífero- el interés por una literatura donde se destaca el trabajo formal. La materialidad de la palabra es uno de los ejes que vertebran su poética, donde los términos de la dicotomía de forma y contenido se fusionan teóricamente cuando concluye que "la forma es el contenido, y el contenido es la forma" y donde, en consecuencia, "la escritura no es acerca de algo; es ese algo" (Beckett: 1978, p. 120). ${ }^{2}$ Beckett emplea estas frases en su ensayo sobre Finnegan's Wake, "Dante...Bruno.Vico.. Joyce", cuyo alcance programático para su propia obra ha sido señalado por la crítica. Lo que subyace a esta formulación teórica es el problema de la imposibilidad de la comunicación, acaso el tema central de la obra beckettiana, y la antitética pulsión de seguir escribiendo a pesar de eso -y también- precisamente sobre eso. Esta investigación parte de la idea del valor metaliterario que revisten los pasajes en que se trabaja con el imaginario de la fluidez: allí donde el texto se vuelve sobre su propia materia -sobre el lenguaje- se repiten elecciones léxicas provenientes del universo de lo líquido. El objetivo será indagar sobre las implicancias específicas que aporta a la cuestión del lenguaje en Beckett este universo metafórico, así como identificar qué aspectos de la fluidez le interesan al autor para trabajar en paralelo a la naturaleza de la palabra. Partimos de la hipótesis de que las metáforas relacionadas a lo líquido le permiten a Beckett explorar la materialidad del lenguaje en su límite con el silencio, y, en última instancia, al silencio como parte del lenguaje y como noción a explorar en la literatura.

1. Mauthner, Fritz. Op. cit., pág. 36.

2. Este ensayo luego integraría Our Exagmination Round His Factification for Incamination of Work in Progress. 
La poética del lenguaje líquido se comienza a delinear en "Asunción", el primer relato que publicó Beckett en 1929 en la revista transition, en el mismo número en que publicó el ensayo que hemos citado, "Dante...Bruno.Vico..Joyce". Este trabajo se propone como una lectura en clave programática de "Asunción", que fue su carta de presentación como escritor de ficción. Para ahondar en el origen de este imaginario del escritor en ciernes que era Beckett por aquel entonces, el Beckett más desconocido, anterior a Esperando a Godot (1949) y a la trilogía de Molloy (1951), Malone muere (1951) y El innombrable (1953), se presentará un análisis de la forma que adopta en Sueño con mujeres que ni fu ni fa, la primera novela del autor, escrita en la primera mitad de 1932 pero publicada de forma póstuma recién en 1992. Al momento de reflexionar sobre las claves que hacen del agua un elemento significativo en su comparación con la naturaleza del lenguaje, resultará útil recurrir a la obra de Fritz Mauthner, filósofo del lenguaje y empirista austríaco en quien Beckett encontró un marco teórico -aunque no el único-para sus ideas en torno a la palabra. Esta intertextualidad se vuelve ineludible si se considera que Mauthner emplea estas mismas referencias metafóricas al abordar la esencia del discurso humano en su obra Contribuciones a una crítica del lenguaje, donde un apartado lleva por título "Cauce del lenguaje" (las itálicas son mías) y en cuyo interior se desarrollan varios símiles acuáticos. Por último, pondremos el foco sobre la carta a Axel Kaun de 1937, en la cual el propio Beckett llega a una suerte de formulación teórica sobre el tipo de uso del lenguaje que propone mediante la articulación con este campo léxico.

\section{Asunción: "al maldecir la corriente de susurros, él había subido el nivel de la inundación"}

En junio de 1929, Samuel Beckett publica su primer relato, "Asunción", en la revista transition: An International Quarterly for Creative Experiment. El texto reviste un valor singular en tanto punto de partida de la poética beckettiana y lo hace en diálogo estrecho con el ensayo presentado en el mismo número (pp. 16-17), "Dante...Bruno. Vico..Joyce”. Como señala Lucas Margarit en “Asunción’ o cómo iniciar una poética del desgarro", Beckett irrumpe en la escena literaria con estos dos textos en los que ya presenta algunos de los motivos que recorrerán toda su obra: "la naturaleza de la escritura, su materialidad en tanto acto de creación", la elaboración de "un lenguaje nuevo", "la estructura cíclica de la historia, su repetición", la idea que expresa en el ensayo de que "la forma es el contenido y el contenido es la forma", el "interés por la figura del creador y su obra", y el ensimismamiento del artista ante la imposibilidad de la comunicación (Margarit: 2015, pp.14-15).

"Asunción" es un relato innegablemente metaliterario puesto que narra un proceso de creación verbal, un movimiento tortuoso del silencio al sonido. Siendo que constituye la irrupción de Beckett en el campo literario, el relato puede funcionar, en última instancia, como mise en abyme de su surgimiento como escritor, hecho sobre el que volveré al final de este apartado. Comencemos por el inicio de "Asunción": "Él podría haber gritado y podía no haberlo hecho"3 (Beckett: 2015, p. 29). Esta primera oración introduce una tensión entre la verbalidad -o al menos el sonido- y el silencio, que articulará el tema de la angustia del artista ante el acto de creación en los cinco párrafos que conforman el relato. El sujeto de esa tensión inicial se da a conocer al lector en este primer párrafo pero sin ofrecer grandes detalles, pues como nota O'Hara, el lenguaje de "Asunción" está lleno de "metáforas que empantanan las afirmaciones directas" (O'Hara: 2015, p.48). Aparecen de inmediato dos figuras, la de un bufón y la de un organista, en ambos

3. Las citas de "Asunción" provienen de la traducción de José Francisco Fernández para la edición bilingüe de EUFyL del año 2015 , única versión publicada en castellano de este relato inaugural. 
casos en escenas ociosas: el bufón se balancea sin cesar sobre su bastón y el organista sueña con las manos en los bolsillos. Desde un inicio el hombre de "Asunción" se asocia por medio de estas dos metáforas a figuras de artistas alejados de su trabajo: aislados e inactivos. Lo próximo que se dice acerca del personaje tiene que ver con su materia particular de trabajo, las palabras. $\mathrm{Al}$ respecto, leemos que "hablaba poco y, cuando lo hacía, de forma casi áspera" (Beckett: 2015, p. 29), en lo que lo emparenta con las figuras del bufón y el organista: no ejercita su arte, y cuando lo hace, lo logra con cierta deficiencia que se adelantaba en esa tensión manifiesta en la primera oración. De este hombre se destaca un don paradójico de "apaciguar el alboroto con susurros" (İdem, p. 29). Esta habilidad reúne los dos polos que se introducen en la primera oración, el grito y el silencio, y los enfrenta o los acerca como si de un círculo se tratara, donde los extremos de cada elemento se funden en su opuesto: en esta primera instancia, el silencio se figura como el fin de la sonoridad, aquello que la disuelve ejerciendo cierto poder sobre ella. La capacidad de lograr voluntariamente ese efecto silenciador sobre otros lleva a que el narrador lo defina como "en parte un artista" (Ídem, p. 30). La imposición del silencio que ejecutaba sin que nadie lo notara era fruto de "una larga serie de preparaciones sutiles" (Íbid.) por las que el hombre "había trabajado duro en la última media hora y nadie lo había visto" (Íbid.). Sin embargo, ha de destacarse que "producir el efecto deseado en los dientes de su público era lo menos difícil" (Íbid). Aquí aparece la inclinación hacia la creación artística que se resiste a ser regida por la búsqueda de la producción de un efecto determinado en el público. El artista abandona esa comodidad pues "el arte más excelso reduce su significado hasta alcanzar esa perfección inexplicable que nos hace estallar" (Íbid.). La experiencia ante lo bello no es plácida, se describe como un dolor, como "ser lanzado sin aliento a la cumbre de un escarpado promontorio" (Ídem: 31). Este primer pasaje analizado sienta las bases para una lectura en clave metaliteraria de "Asunción".

El párrafo siguiente introduce el universo de la liquidez en relación con el lenguaje cuando el narrador se detiene sobre la paradoja de que este don de acallar el bullicio por medio del silencio no suponga un control sobre el sonido que se gesta dentro de él mismo:

En el silencio de su habitación tenía miedo, miedo de esa ola impetuosa ${ }^{4}$ de furia que aspiraba a realizarse violentamente por medio del sonido. Sentía su implacable resentimiento aprisionado, su deseo de ser liberado en un soberbio grito ebrio que se fundiera con el desorden cósmico. (Ídem, 41).

El grito del comienzo del relato vuelve aquí como algo nuevamente contenido pero con cada vez mayor dificultad. Aparece, a su vez, el deseo de fundirse de ese grito, que tiene una connotación relativa al derretirse, al fluir, en línea con la idea de la "ola impetuosa" de sonidos aprisionados. El hombre contempla esta tensión que O’Hara describe como la de su parte espiritual y su parte física, dado que una vez que la palabra se exteriorice como sonido, esta se volverá parte del mundo material (49). Aquí vemos como comienza a construirse ese lenguaje interno como un lenguaje líquido, que se profundiza unas líneas después, pasando de una ola al mar en su totalidad: "mientras tanto aquel mar de silencio encerrado por el cuerpo alcanzaba una miserable culminación en pequeñas gotas de sonido". 5 El narrador marca la desproporción entre ese mar contenido y las pequeñas gotas que salen por medio de otra metáfora, en esta oportunidad, la de "cocer un huevo en una hoguera", hecho que califica como

\footnotetext{
4. Aquí el original habla de un "violent surge" que Fernández traduce como arranque", pero que en el marco de un relato que trabaja con el campo léxico de lo líquido, he preferido mantener en su acepción de "ola" o "aluvión".

5. Una vez más, propongo una traducción algo diferente a la de Fernández, que traduce "flesh-locked sea of silence" por "mar de silencio rodeado por el cuerpo". A mí me resulta importante que se refleje el rasgo coercitivo del encierro que implica un verbo como "lock" en inglés, distinto de por ejemplo "encompass"; de ahí mi decisión de emplear "encerrado".
} 
"una extravagancia no deseada" (Beckett, 2015: 32). Estas gotas de sonido escapan del control del artista, que le teme a esa voz interna al mismo tiempo que alberga un deseo por liberar ese fluido interno por el dolor que le representa contenerlo: "no era tanto el temor a que su prisionero fuera a escapar, deseaba ardientemente que escapase; le desgarraba la garganta y él lo ahogaba empujándolo con pena y terror" (Íbid., las itálicas son mías). El silencio que impone el artista ahoga al mar de palabras que alberga, en una sintaxis donde silencio y sonido comienzan a ser parte de la misma materia, del lenguaje. Este dolor hace sistema con el dolor propio de la experiencia de lo bello que se describió unas líneas antes en el relato, como si esas primeras "gotas" o proferencias lingüísticas pertenecieran al campo del arte.

El hombre comienza a temer a cualquier cosa que pudiera acabar con su "inhibición involuntaria", y trata por distintos medios de contenerse: drogándose para dormir, callando y decidiendo no salir de su habitación. En este punto el texto presenta un guiño metaliterario muy claro y difícil de traducir: "He felt he was losing, playing into the hands of the enemy transition by the very severity of his restrictions" [las itálicas son mías] (Ídem, p.42), que podría traducirse como "sentía que iba perdiendo, jugando en manos del enemigo transición por la propia severidad de sus restricciones". El nombre de la revista es una de las interpretaciones que se ponen en juego en este pasaje, de modo que mientras el artista impone sus restricciones silenciosas a su verbosidad, que comienza a tomar forma en gotas de sonido, de algún modo se podría estar aludiendo a la publicación en la revista. La voz interna comienza a cobrar vigor y se aproxima la derrota y, a la vez, la asunción del hombre en tanto artista:
Al maldecir la corriente de susurros, él había subido el nivel de la inundación y sabía que llegaría el día en el que no podría seguir negándolo. Aún así permanecía en silencio, en silencio a la espera de escuchar el primer murmullo del torrente que debía destrozarlo. (íbid.)

El lenguaje en "Asunción" se figura como un torrente, una corriente, una entidad líquida que puja desde el interior por salir, por fundirse en el mundo material, por abandonar el ensimismamiento del mundo de los pensamientos. Esa tentación del mundo material se completa en la segunda mitad del relato con la presencia de una mujer de habla "clara y serena" y en cuya "contemplación y absorción" pasaba las tardes mientras "el nivel del agua aumentaba" (Ídem, p.34). Ese in crescendo de la dificultad por contener el mar de sonidos acaba con "una gran tormenta de sonidos (...) alcanzando cotas de vértigo y efervescencia, hasta que, dispersándose, se fundió con el aliento del bosque y el vibrante clamor del mar" (Ídem, p. 35). El fin del hombre, a quien la mujer le acaricia sus "alborotados cabellos sin vida", es al mismo tiempo el fin del relato, como si esa "tormenta de sonido" fuera precisamente esta publicación con la que el autor rompe el silencio. En ese sentido, en última instancia puede leerse como una mise en abyme, un juego especular que vuelve la mirada sobre la propia naturaleza del texto en tanto artificio literario. Siguiendo esta línea de interpretación, el título, que ha sido analizado en su intertextualidad con Balzac y Swedenborg, ${ }^{6}$ puede estar funcionando también como un guiño al acto fundacional de la figura de autor de Beckett en relación con el acto creativo que se describe. Con esta publicación la asunción del título sería la del autor en tanto tal en su introducción en el campo de la literatura.

6. "La plataforma de lanzamiento de 'Asunción"', J.D. O’Hara presenta un análisis intertextual del relato en relación a tres novelas de Honoré de Balzac -Les Proscrits (1831), Louis Lambert (1832) y Séraphita (1834/5)- que a su vez trabajan con ideas tomadas de los escritos de Swedenborg en torno a la idea de la tensión entre espíritu y carne. O’Hara señala que el título se vincula directamente con la elevación a los cielos del serafín en Séraphita, cuyo último capítulo lleva justamente el título de “Asunción". Ver O’Hara, 2015. 
En "Asunción" el lenguaje líquido articula una estética que repara en el tipo de experiencia que produce "el arte más excelso" en donde parece no haber una relación de control sobre el objeto, sino más bien una relación en donde hay una tensión entre el control y la naturaleza propia del lenguaje, un resto que escapa. Además, la liquidez parece vincularse con otro aspecto de la concepción del lenguaje de Beckett que tiene que ver con darle la espalda al significado unívoco, fijo. Aquí "Asunción" deja otro guiño en la mención del poeta George Meredith, cerca del final. O'Hara postula que la mención alude a la última estrofa de "Modern love": Entonces cada uno aplicó al otro ese cuchillo fatal,/ el cuestionamiento profundo, que sondea con dolor sin fin./Ah, qué respuesta polvorienta recibe el alma/ afiebrada en busca de certezas en esta nuestra vida" (Ídem, p. 66). El artista se tranquiliza abrazando la duda, en lo que constituye otra pauta para pensar en el tipo de lectura que ha de hacerse de un texto como "Asunción".

En este punto, para poder acercarnos a este tipo de concepción sobre el significado que no es fijo, que fluye y se desplaza, resultará útil recurrir a la obra de Fritz Mauthner. Luego de que Richard Ellman señalara por vez primera la conexión entre Beckett y Fritz Mauthner en su biografía de James Joyce de $1959^{7}$, en las últimas décadas del siglo XX surgió una nueva área de interés en torno a la influencia que tuvo sobre la concepción del lenguaje al interior de la poética beckettiana. Autores como Linda Ben-Zvi, Edith Kerman, James Knowlson y John Pilling han tratado esta relación en numerosas oportunidades, haciendo análisis acerca del modo en que Beckett halló en Contribuciones a una crítica del lenguaje8 el marco filosófico para su propio escepticismo en torno al lenguaje y la comunicación. Un análisis pormenorizado de esta relación intertextual escapa las limitaciones y objetivos de este trabajo, pero Ben-Zvi ofrece una síntesis que resultará imprescindible en lo que sigue: "al colocar el lenguaje en el centro de la crítica, subsumiendo todo conocimiento en él, y luego negándole su eficacia básica de forma sistemática, Mauthner ilustra la posibilidad de utilizar el lenguaje para criticarlo"(Ben-Zvi: 1980, p. 183). Esa centralidad y nulidad lingüísticas se encuentran en el corazón de la poética beckettiana.

En la primera parte Contribuciones, dedicada a la esencia del lenguaje, Mauthner repara en el hecho de que lo que entendemos por "lenguaje" es una abstracción, puesto que en todo caso cada individuo tiene un lenguaje particular. Es en ese contexto temático que introduce la metáfora del cauce del lenguaje para poder representar su infinita mutabilidad: "Los diferentes lenguajes con los que está acostumbrada a trabajar la ciencia lingüística semejan corrientes, en las cuales, y desde un punto de vista espacial, cada gota fluye en medio de otras" (Mauthner: 1976, pp. 35-36). El lenguaje de cada individuo es "un río eterno y mudable" y donde más se destaca este hecho según Mauthner es en el caso de los artistas. La metáfora del agua en Mauthner apunta sobre todo a la mutabilidad y la particularidad del lenguaje.

Beckett aprecia precisamente aquél uso particular lenguaje en Work in Progress de Joyce en "Dante...Bruno.Vico..Joyce", donde observa una apuesta por un lenguaje primitivo, directo y económico para resistir a las limitaciones del inglés, atacando "el lenguaje convencional de los astutos artífices literarios". Al respecto, Margarit afirma que se le da a la escritura "un perfil donde el sentido se encuentra en el uso particular de la palabra y no en la idea" (Margarit: 2015, p. 15). Tanto en "Asunción" como en "Dante...Bruno. Vico.. Joyce", está la idea de un lenguaje que está vivo y muta: "las palabras no son las contorsiones amables de la tinta del impresor del siglo XX. Están vivas" (Beckett: 1984,

\footnotetext{
7. Según Ellmann, en 1932 un James Joyce casi ciego "le pedía al joven que le leyera pasajes de Beiträge zu einer Kritik der Sprache ("Contribuciones a una crítica del lenguaje") en donde la visión nominalista del lenguaje parecía ser algo que Joyce buscaba” (JJ, 648-649). Más adelante Beckett aclaró que en verdad Joyce le había prestado el volumen para que lo leyera (ver en Ben Zvi, 1980: 198).

8. En adelante, Contribuciones.
} 
p.28). En "Asunción", el protagonista se encuentra solo en una habitación hasta la llegada de la mujer. Sobre este hecho tan extendido en las obras de Beckett, Margarit afirma:

El artista 'es' en soledad porque el ensimismamiento es una manera de concentrar el pensar en el decir, lo que conduce, en la medida que no hay dos hombres que hablen la misma lengua, a aquella aserción de Fritz Mauthner (...): 'Y todavía no ha sonado el lamento de que toda la miseria de la soledad viene solamente del lenguaje. (Ídem: 18)

Esa limitación del lenguaje en Mauthner culmina en su famosa afirmación de que "sería tiempo de aprender a callar" (Mauthner: 228). En el interés de Beckett por el silencio hay reminiscencias de Mauthner, y en particular en "Asunción" donde se libra la lucha entre el silencio y el verbo, necesariamente se llega a la idea de un ciclo: el silencio acaba con la palabra y viceversa, los dos términos son condiciones de posibilidad de su opuesto. Las metáforas vinculadas a la liquidez permiten que se piense en el silencio ora como el solvente donde el sonido (comportándose como soluto) se disuelve, ora al revés. En Beckett silencio y sonido pertenecen al lenguaje de igual modo. Este primer relato prefigura, por tanto, uno de los temas con los que Beckett experimentará para atacar el lenguaje "desde adentro": el silencio. Aquí aún está trabajado a nivel diegético, en el relato que es esencialmente sobre la lucha por contener la palabra.

\section{"El corrosivo mar de fondo del Arte" en Sueño con mujeres que ni fu ni fa}

Beckett escribió Sueño con mujeres que ni fu ni fa [Dream of Fair to Middling Women] en el verano de 1932 en París, lo cual la convierte en su primera novela. Sin embargo, la obra permaneció inédita durante sesenta años. Luego de haberla enviado a varias editoriales que la rechazaron en Irlanda, en 1933 el autor probó suerte en Inglaterra. Tras este segundo intento fallido Beckett desistió de la idea de publicarla, y en cambio optó por trabajar lo que en 1934 terminó siendo More Pricks Than Kicks, una colección de cuentos donde reunió materiales de Sueño con mujeres que ni fu ni fa [en adelante Sueño] junto con otros nuevos. En More Pricks Than Kicks hay una mención a su primera novela, que aparece como un libro demorado durante años en el estadio de labor limae, en un párrafo que abona la idea de que por aquel entonces aun estaba la voluntad de publicarla en algún momento del futuro (Beckett: 2010, p. 134). Más adelante, Beckett llegaría a renegar de sus primeros trabajos, incluyendo Sueño, y es así que la obra se publicó recién de forma póstuma, en 1992.

En su trabajo "Infernal Streams - Beckett's Rivers", Mark Nixon analiza la función de los ríos y de otros cuerpos de agua, y en relación a ellos de los puentes y los muelles, en Sueño. Allí destaca la influencia directa de Joyce, en particular de Finnegan's Wake, al momento de su escritura, dado que Beckett venía de traducir la sección "Anna Livia Plurabelle" al francés junto a Alfred Péron. En una carta a Thomas Mc Greevy, Beckett se refiere a esta tarea como la traducción de "la parte de los ríos"9 "Anna Livia Plurabelle" es la sección de Finnegan's Wake donde Joyce procuró captar la mitología del río Liffey, que opera como emblema de lo femenino y que, en tanto personaje que habla, da origen al texto. Joyce concebía esta sección como un intento por "subordinar las palabras al ritmo del agua" (Ellmann: 1982, p.564). 
La acción en Sueño transcurre en parte en Dublín, motivo por el que no ha de extrañarnos la presencia de los ríos y canales de la ciudad. La hipótesis de Nixon es que en la novela de Beckett, estos cuerpos de agua -así como los puentes y los muelles- vienen a destacar los estados de transición, las "posturas intermedias" a las que el título referiría ("middling" proviene de "middle", de modo que se alude a una noción de medianía que se ha traducido como "ni fu ni fa"). El río en tanto locus habitualmente asociado al origen de la vida pero también como lugar de la muerte (Nixon repara en la recurrencia de suicidios que ocurren en ríos en las obras de Beckett), y, por un lado los puentes, por la simple razón de conectar dos espacios, y los muelles, que pueden pensarse como "puentes truncos", como espacios donde se acentúan los límites, son todas imágenes idóneas para explorar las disyunciones beckettianas. Al respecto, cabe recordar la aporía que hemos analizado del comienzo de "Asunción": "Podía haber gritado y podía no haberlo hecho" (Beckett: 2015, p. 29).

Sueño comienza con un brevísimo apartado de dos pocos párrafos dedicados a la infancia de Belacqua. A continuación, la novela salta en el tiempo al presente del personaje en una escena en donde se introduce el imaginario del agua con Belacqua sentado en el muelle de Carlyle bajo la llovizna. Es la escena de su despedida de Smeraldina-Rima, su novia que parte a Viena para estudiar piano. La decisión de situar este comienzo en un muelle está lejos de ser inocente: la escena puede entenderse como símbolo del quiebre que se produce con la partida de Smerry. Así como el muelle termina en el agua, el vínculo entre los novios llega aquí a un límite, a una desconexión. Sin embargo, esta no es la única tensión o ruptura que se articula en la escena. El narrador pone el foco en los esfuerzos que le supoe a Belacqua el juego de contener y provocar su angustia, en una escena análoga al juego oscilante de contención y liberación que analizamos en "Asunción".

Estaba sentado esforzándose en provocar el pequeño surtidor de lágrmas que sirviera a su descargo. Nada más sentirlas acudir, ponía la mente en blanco y esperaba a que se sosegase la comezón. Primero le daba la vuelta con cuidado en la imaginación hasta que se pegaba un batacazo y se mareaba pensando en ella; después, ni un segundo más tarde, paraba y vaciaba su ánimo con brusquedad, de forma que se detenía el flujo; éste se bloqueaba y se mandaba de vuelta para un da capo (Beckett: 1996, p. 14).

En esa inclusión final de la expresión "da capo" comienza a construirse una idea del proceso concebido como el de una composición musical. El término "da capo" le indica a los intérpretes que deben repetir la música previa a su inclusión en la partitura. Belacqua recurre así una y otra vez al estímulo del gesto de despedida de Smeraldina -sacudiendo su boina verde en el aire- con el fin de producir un efecto estético cíclico. El narrador se referirá al mecanismo como una técnica que Belacqua depura hasta que pierde el control y "los pistones de su mente se quedaron quietos" en lo que se describe como una "avería total de la máquina" (Ídem, p. 15). En este punto trata de dar con alguna otra imagen que vuelva a producir el efecto de exaltar su angustia como lo hacía la boina, "una mirada al estilo de Rasima en los ojos hundidos de la muchacha" (Íbid.). La experiencia de Belacqua con Smeraldina está mediada en Sueño por figuras provenientes o bien de sus lecturas, en este primer caso de la Biblia, o bien del mundo del arte. De este modo, los muslos de ella serán caracterizados como "botitticellianos" unas páginas más adelante y el narrador dirá que "creía ver en ella el vivo retrato de la Madonna Lucrecia del Fede" (Ídem, p. 27).

La figura de Belacqua comienza a figurarse así ligada a la de un artista, en primera instancia como artífice o compositor ensimismado en la creación de esa escena de despedida, y es por eso que encontramos claves de lectura en estos pasajes donde se trabaja con escenas de "poiesis", de creación artística. El desplazamiento que se produce en aquella escena inicial, además de la ruptura en el vínculo amoroso señalada por 
Nixon, tiene que ver con la tensión entre dos tipos de angustia: aquella que le produce la despedida de su amada, y la que toma su lugar, a saber, "la pena mucho mayor de ser un hijo de Adán, condenado a soportar una mente insubordinada" (Ídem, p. 16). Esta segunda angustia más profunda se vincula con su rol como artista. El ensimismamiento de Belacqua en ese estado de "tristeza trascendental", se ve interrumpido por "la insolente intromisión del mundo" (Íbid) cuando un guardia del muelle lo echa, en un momento reminiscente de la interrupción del plano material que analizamos en "Asunción". Así, se refuerza la idea del estado de Belacqua como separado del resto del mundo, en una experiencia de otro orden, acaso artístico.

Para ahondar en un análisis metaliterario, Sueño provee una ocasión singular al vincular la música de forma explícita con la literatura a través de la historia de Lîng-Liûn y las cañas de bambú que, en tanto instrumentos, emiten sonidos iguales al de la voz humana y al canto del ave fénix. El narrador expresa su deseo de que "al menos algunos de nuestros personajes puedan representar el papel de un liû-liu" para poder "escribir un librito que fuera sólo melódico (...) una teleofonía de una sola figura que sería un placer escuchar" (Ídem, p. 22). De forma paulatina, esa asociación inicial de Belacqua con la figura del compositor se irá aproximando entonces a la de Belacqua como escritor.

Así como Belacqua moldea su despedida como una experiencia estética en el espacio del muelle de Carlyle, a orillas del Mar Irlandés, en el apartado "Und", la escena en que el personaje explicita su voluntad de escribir un libro se da a bordo de un barco de regreso al terruño. Belacqua expresa allí el programa de su escritura:

Escribiré un libro en el que la frase tenga conciencia de ser inteligente y avispada, pero inteligente y avispada de manera distinta a sus vecinas de página. Las rosas henchidas de una frase catapultarán al lector a los tulipanes de la frase siguiente. La experiencia del lector tendrá lugar entre las frases, en el silencio, le será comunicada en los intervalos, no en los términos del enunciado, entre las flores que no pueden coexistir, los períodos antitéticos (nada tan simple como lo antitético) de las palabras, su experiencia ha de ser amenaza, milagro, memoria de una trayectoria inefable (Ídem, p. 167) [las itálicas son mías].

Este fragmento citado da inicio a la escena más denodadamente metaliteraria de Sueño, donde el lector halla claves de lectura para la poética en la que se inscribe la novela, donde, en el marco de la exploración de las posiciones intermedias o "middling", aparece nuevamente el tema del silencio. En ese sentido, Belacqua cruza el puente que une la proa y la popa y agrega: "expondré los silencios con mayor destreza de la necesaria para clavar las mariposas del vértigo" (Ídem). Al igual que en "Asunción”, el trabajo en torno a la expresión verbal del silencio en la literatura se construirá por medio de la comparación con otras expresiones artísticas. Aparecen entonces en su imaginación el retrato de Van Ryn donde Belacqua aprecia "una disfacción, un désuni" (İdem), y la música de Beethoven donde "el enunciado musical incorpora una puntuación de deshicencia" y las composiciones son "devoradas por terribles silencios" (Íbid., 168). Aquí comprobamos nuevamente la expresión de dicha puesta en tensión de la música y por extensión de la literatura con el silencio a través del imaginario de la fluidez, puesto que Belacqua concluye que se trata del "corrosivo mar de fondo del Arte" y del cupio dissolvi, es decir, el deseo de disolución (Ídem).

Si alguna vez termino un libro, Dios no lo quiera, estando el oficio como está, será un engendro destartalado, ruinoso, un cacharro de hojalata, sujeto por trozos de guita, y al mismo tiempo tan refractario a desarmarse por pura veleidad como la máquina de volar de los hermanos Wright a dejarse convencer para levantar el vuelo (Ídem). 
Este momento de Belacqua como escritor cierra con este pasaje que nuevamente puede interpretarse como instancia que opera como reflejo sobre el libro que el lector tiene entre manos y su poética de exploración de los estados intermedios, como el de apostar por la expresión de una literatura que se da entre el silencio y la expresión.

\section{La carta alemana: ¿atormentar las palabras?}

La carta que Beckett envió a su amigo Axel Kaun en 1937 se ha convirtido en un texto ineludible a la hora de inscribir a Beckett en las discusiones sobre el modernismo tardío o el posmodernismo, sobre todo en lo que hace a la problematización del lenguaje y del significado. ${ }^{10}$ La llamada carta alemana contiene testimonios directos como hay pocos en otros textos de Beckett sobre sus ideas en torno al lenguaje y la literatura, la relación de las otras artes con la literatura, sus apreciaciones sobre el inglés y otras lenguas que conoce y su relación con otras figuras literarias.

Realmente me resulta cada vez más difícil, y aún sin sentido, escribir un inglés oficial. Y cada vez más se me aparece mi idioma como un velo que uno debe rasgar para acceder a las cosas que están detrás (o a la nada que está detrás) . (Beckett: 1996, p. 90) ${ }^{11}$

En este fragmento se vislumbra lo importante que resulta esta carta -escrita en un alemán imperfecto- para pensar la decisión que tomaría el autor de comenzar a escribir en francés. Es allí donde Beckett manifiesta de forma explícita su voluntad de apostar por una literatura que rompa con las convenciones gramaticales y estilísticas, y la consecuente dificultad que le presentaba su lengua madre en ese sentido. En su trabajo "'Steady Stream ... Mad Stuff ... Half the Vowels Wrong ...': Water, Waste and Words in Beckett's Plays", Katherine Weiss se detiene sobre un aspecto antes inexplorado de la carta, a saber, que Beckett “(...) utiliza imágenes relacionadas con el agua para cuestionar su capacidad de escribir en su inglés nativo" (Weiss, 2017: 78). Este hecho prueba hasta qué punto esta relación con la liquidez es indisociable de su idea particular de lenguaje: no es únicamente un universo simbólico al que recurre en sus obras literarias, sino que también constituye un recurso que emplea al reflexionar teóricamente sobre su medio.

Gramática y estilo. Me parece que han llegado a ser tan caducos como un traje de baño Biedermeier o la imperturbabilidad de un "gentleman". Una máscara. Ojalá llegue el momento (que ya existe, gracias a Dios, en ciertos círculos) en el que el lenguaje sea usado del modo más eficiente allí donde se abuse de él del modo más hábil. Puesto que no podemos eliminarlo de una vez al menos no queremos omitir nada que pueda contribuir a su descrédito. Hacerle un agujero tras otro hasta que lo que se esconde detrás, sea eso algo o nada, comience a filtrarse... No puedo imaginarme ningún objetivo más alto para el escritor de hoy. (Beckett: 1996, p. 90)

Para Weiss, el detalle del traje de baño Biedermeier -ignorado durante muchos años por la decisión de Esslin de reemplazarlo en su traducción por un traje de baño victoriano, en una apuesta por un equivalente más "familiar" para el público inglés- es significativo para el ataque a la gramática y al estilo que se plantea. La era Biedermeier (1815-1848) había surgido como una reacción ante la agitación política y la ideología independentista e individualista de la Revolución Francesa, con valores como el del regreso de la familia. En cuanto al arte, esta era estuvo signada por las manualidades

10. Ver, por ejemplo, los análisis de Begam 37-9, Boulter 19-20, Conner, 19, Coughlan 76, Fifield 73-4, y McDonald 36. 11. Traducción del alemán de Ana María Cartolano en Beckettiana. Cuadernos del seminario de Beckett, Año 5, 1996, pp. 89-91. 
(las llamadas "arts and crafts"), un tipo de arte meramente decorativo, contra lo que Beckett escribió por ejemplo en "Tres diálogos". En la comparación de la obsolescencia de la gramática y el estilo con este atuendo, escribir de acuerdo a las estructuras tradicionales del inglés y de su tradición aparece entonces como un gesto anticuado, atrasado con respecto a su tiempo. Weiss agrega que no hay evidencias de que haya existido este estilo de trajes de baño, con lo cual Beckett podría estar simplemente comparando un uso tradicional del inglés con una prenda imaginada que cifraría lo conservador de una era. Sobre el final de la cita encontramos, además del traje de baño que remite a la playa y a la natación, otro conjunto de elecciones léxicas que pertenecen al imaginario líquido. Si la lengua oficial es un velo, quiere decir que hay algo que permanece oculto detrás de su superficie, que ha de ser perforada "hasta que lo que se esconde detrás, sea eso algo o nada, comience a filtrarse" (las itálicas son mías). La imagen es la de un líquido colándose por los agujeros infligidos sobre una superficie que lo mantenía a raya, en lo que supone una liberación del fluir del lenguaje por los orificios pues "no podemos eliminarlo de una vez" (Beckett: 1996, p. 90).

Para reforzar su crítica a un uso anticuado del lenguaje en tanto materia, a continuación el autor trae a la carta las comparaciones de la literatura con otras artes, como vimos en el caso de Sueño.

¿O debe la literatura seguir sola, en aquellas viejas sendas corrompidas, hace ya tiempo abandonadas por la música y la pintura? ¿Se esconde algo paralizantemente sagrado en la perversidad de la palabra que no forma parte de los elementos de las otras artes? ¿Hay alguna razón por la cual esa materialidad terriblemente arbitraria de la superficie de la palabra no pueda ser disuelta, como por ejemplo la superficie sonora corroida por grandes pausas negras en la séptima sinfonía de Beethoven, de modo que, durante páginas enteras, no podemos percibir otra cosa que quizás un estrecho sendero de voces suspendido en vertiginosas alturas que eslabona insondables abismos de silencio? (Beckett: 1996, p. 90)

En el marco de la pregunta por la veneración que nota en torno a la palabra, que no permite que "sea devorada", vuelve a aparecer la idea de este ataque a las convenciones del lenguaje, pero aquí expresado como una disolución, es decir, un volverse líquido. Sobre este pasaje, Weiss concluye: "en última instancia, Beckett quiere que el lenguaje sea fluido" (80), lo cual implica una literatura que empuje su materialidad al límite de la desintegración como ocurre en las artes plásticas o en la música.

El final de la carta se detiene sobre la paradoja de lo que el propio autor llama "la disonancia de medios y uso". Beckett reconoce que no es tarea sencilla "inventar, de alguna manera, un método para representar con palabras esta actitud desdeñosamente burlona frente a la palabra" (Beckett: 1996, pp. 90 -91). Aquí resuena el tema que obsesionara a Mauthner, el lenguaje como medio para llevar adelante su propia crítica. La empresa está destinada a fallar, Beckett habla de "contentarse con muy poco por ahora”. ¿Pero de qué forma se sugiere en la carta que se podría llevar adelante esta tarea? Nuevamente a través de la figura de Beethoven ha ingresado el silencio como agente "devorador" de la música, y de allí, como desafío para la expresión escrita. La elección de "disolver" tiene también este matiz de "perderse" en: el lenguaje puede ser devorado por el silencio. La carta cierra con una formulación de la tarea por delante, y una vez más, ingresa un ítem lexical vinculado al campo del agua en un pasaje de difícil traducción: "Eine Wörterstürmerei im Namen der Schönheit", que Cartolano traduce como "una iconoclastia de las palabras en nombre de la belleza" (Beckett: 1996, p. 91). "Wörterstürmerei" es una palabra que no existe en el alemán y que el autor creó sobre la base de "Bilderstürmerei" (iconoclastia), de allí la elección de la traductora de la edición que hemos citado. Leland de la Durantaye sugiere que la mejor traducción 
sería en todo caso la de "logoclastia" 12 , por dar cuenta del origen de "iconoclastia" y por reflejar el morfema "wörter". Sin embargo, para un hablante nativo de inglés como era Beckett, la palabra configura un pun (un juego de palabras) que se ha traducido como "word-storming", es decir, algo así como "atormentar las palabras" ("Sturm" es tormenta en alemán). Este juego de palabras de la carta que no puede mantenerse en español remite, tanto en alemán como en inglés, una vez más a una imagen vinculada al imaginario del agua allí donde Beckett enuncia su intención literaria de desacralizar la materialidad de la palabra, o, como leemos en el poema Cascando, de 1936: "moliendo el suero inalterable// de las palabras" (Beckett: 1970, p. 89). Basta recordar el comienzo de este poema "por qué no simplemente perder toda esperanza / de ser ocasión de / un derramamiento de palabras" (Îbid.) para verificar que también presenta el campo léxico de los fluidos en estrecha vinculación con un programa de escritura. En los versos citados encontramos pun digno de atención: "the unalterable whey of words" es "el suero inalterable de las palabras", pero suena exactamente igual a "the unalterable way of words", es decir, "el modo inalterable de las palabras". Creemos que aquí el poema apunta también en dirección a atacar aquello que hace que las palabras no sean objeto de experimentación en su materialidad como sí ocurre en los casos de la música y la pintura.

\section{Reflexiones finales}

"Asunción" sienta las bases para lo que podemos llamar la poética del lenguaje líquido en Samuel Beckett, pues allí se formula por vez primera la estrecha vinculación entre el lenguaje y los cuerpos de agua que se repetirá en numerosas oportunidades en el corpus del autor. Esta propuesta continúa en desarrollo en los escritos aquí analizados de su producción de la década del '30, Sueño con mujeres que ni fu ni fa y la carta alemana de 1937. El universo simbólico del agua es central en la constitución de su poética esencialmente porque los pasajes que contienen esa homologación entre la palabra y los líquidos abonan reflexiones metaliterarias, vehiculizando nociones sobre la concepción del lenguaje y la literatura que operan en sus textos.

A la luz del análisis del corpus seleccionado, podemos concluir que en los símiles entre el lenguaje y el universo de los líquidos Beckett encuentra un campo semántico que le permite destacar la naturaleza incontrolable y permanente del lenguaje en tanto materia de la escritura, expresar la noción de su implacable mutabilidad y particularidad, en especial en el caso del lenguaje de un artista, y, sobre todo, explorar la relación de la escritura con el silencio.

En lo que respecta a la naturaleza mutable y particular del lenguaje, Beckett abreva en -o por lo menos dialoga con- los escritos de Mauthner, quien emplea la idea de los cauces para trabajar el lenguaje como una abstracción compuesta por partes que se mantienen en permanente movimiento y transmutación. El lenguaje en Beckett es un lenguaje vivo, y su poética no pretende fijar significados ni referencias sino apostar por un fluir de ambigüedades, dudas y aporías. Como se señaló en el análisis de Sueño, hay una apuesta por una literatura de los estados intermedios o "middling".

En "Asunción" nace la exploración de uno de esos estados en un primer acercamiento a una literatura que se mueve entre el silencio y la expresión, en un camino progresivo de horadación del lenguaje. Este relato inaugura esa línea de trabajo en la narración del

12. El autor dedica un apartado (titulado "Word-storming or Logoclasm") a este fragmento de la carta y a la historia de sus traducciones en Beckett's Art of Mismaking. 
movimiento que va desde el silencio a la escritura, expresado por medio del lenguaje entendido como líquido. Leído en clave metaliteraria vimos como opera en tanto asunción de Beckett como autor. Allí aparece la primera formulación de un programa de escritura que explorará la tensión entre los términos opuestos del silencio y la palabra donde el silencio se concibe como parte de la literatura, ora como solvente donde la expresión verbal se disuelve, ora al revés. El silencio en tanto noción a ser explorada en la escritura se problematiza nuevamente en Sueño con mujeres que ni fu ni fa y en la carta alemana, instancias donde Beckett recurre también a comparaciones entre la literatura y otras artes. En ambos casos, esta problematización se da en pasajes donde hay una fuerte presencia del imaginario líquido a la hora de trabajar con la materialidad de la palabra y su posible disolución.

Las producciones tempranas que hemos analizado permiten vislumbrar la paradoja central del acto creativo de la poética beckettiana, que se resume muy bien en "Tal Coat", la primera parte Tres diálogos: "La expresión de que no hay nada que expresar, nada con que expresar, nada desde donde expresar, ningún poder de expresar, ningún deseo de expresar, junto con la obligación de expresar" (Beckett, 1984: 139). Beckett insistirá en "inventar de alguna manera un método para expresar esta actitud despectiva hacia las palabras" (Beckett: 1984, p. 53), de modo que su programa de escritura se plantea desde el inicio como una tarea destinada a fallar pero también a seguir perpetuándose en una poética que concibe el fracaso como parte esencial de la labor artística. 


\section{Q Bibliografía}

» Beckett, S. (2015). Asunción, Edición Bilingüe. Prólogo de Lucas Margarit, epílogo de J.D. O'Hara. Buenos Aires: EUFyL.

»Beckett, S. (1996). “Carta alemana de 1937” en Cartolano, Ana María (trad.), Beckettiana. Revista del seminario de Beckett, Año 5, pp. 89-91.

»Beckett, S. (1978) “Dante...Bruno.Vico.. Joyce” en Jenaro Talens (ed.), Detritus. Barcelona: Tusquets.

» Beckett, S. (1990). “Not I" en The Complete Dramatic Works. Londres: Faber and Faber, pp. 373-83.

»Beckett, S. (1984).“Three Dialogues” en Ruby Cohn (ed.), Disjecta: Miscellaneous Writings and a Dramatic Fragment. Nueva York: Grove Press, pp. 138-145.

» Beckett, S. (2010). More Pricks Than Kicks [1934], Londres: Faber \& Faber.

» Beckett, S. (1970). Poemas. Traducción, estudio preliminar y notas de Jenaro Talens. Barcelona: Barral Editores.

»Begam, R. (1996). Samuel Beckett and the End of Modernism. Stanford: Stanford University Press,.

"Ben-Zvi, L. "Samuel Beckett, Fritz Mauthner and the Limits of Language" en PMLA, Marzo 1980, vol. 95 N.2., pp 183-200.

"Boulter, J. (2008). Beckett: A Guide for the Perplexed. Londres: Continuum.

"Connor, S. (1988). Samuel Beckett: Repetition, Theory and Text. Oxford: Blackwell.

»Coughlan, P. (2000). “'The Poetry is Another Pair of Sleeves': Beckett, Ireland and Modernist Lyric Poetry." en Jennifer Birkett and Kate Ince, Samuel Beckett. Londres: Longman, pp. 65-82.

»De La Durantaye, L. (2016). Beckett's Art of Mismaking. Massachusetts: Harvard University Press.

»Ellmann, R. (1982) James Joyce. The First Revision of the 1959 Classic. Nueva York: Oxford University Press.

»Esslin, M. "Samuel Beckett and the Art of Radio," Mediations: Essays on Brecht, Beckett and the Media (Nueva York: Grove Press, 1982): 125-54; rpt. en S. E. Gontarski (ed.), On Beckett: Essays and Criticism. Nueva York: Grove Press, 1986, p. 366.

» Fifield, P. (2013). Late Modernist Style in Samuel Beckett and Emmanuel Levinas. Nueva York: Palgrave Macmillan.

» Kalb, J. (1994). “The mediated Quixote: the radio and television plays and 'Film”" en John Pilling (ed.), The Cambridge Companion to Samuel Beckett. Cambridge: Cambridge University Press, pp 124-44.

»Margarit, L. (2015). “'Asunción’ o cómo iniciar una poética del desgarro” en Beckett, Samuel. Asunción, Edición Bilingüe. Buenos Aires: EUFyL, 2015.

"Mcdonald, R. (2006). The Cambridge Introduction to Samuel Beckett. Cambridge: Cambridge University Press.

»Mauthner, F. [1906] Contribuciones a una crítica del lenguaje. Traducción del 
alemán por José Moreno Villa. México: Juan Pablos Editor, 1976.

» Nixon, M. (2008) “Infernal Streams - Beckett’s Rivers” en Samuel Beckett Today / Aujourd'hui, 2008, Vol. 20, Des éléments aux traces: Elements and Traces, pp. 33-47.

"O’hara, J. D. (2015). "La plataforma de lanzamiento de 'Asunción'” en Beckett, Samuel. Asunción, Edición Bilingüe. Buenos Aires: EUFyL.

»Perloff, M. (1999) "The Silence that is not Silence: Acoustic Art in Beckett's 'Embers'” en Oppenheim, L., (Ed.) Samuel Beckett and the Arts: Music, Visual Arts, and Non-Print Media Nueva York y Londres: Garland. Consultado por última vez el 02-05-2020 en http://writing.upenn.edu/epc/authors/perloff/beckett.html

» Weiss, K. (2017). “'Steady Stream ... Mad Stuff ... Half the Vowels Wrong ...': Water, Waste and Words in Beckett's Plays", Tennessee Philological Bulletin. Vol.65 87. ISBN: 77. 
